AperTO - Archivio Istituzionale Open Access dell'Università di Torino

\title{
Age at surgery for undescended testis and risk of testicular cancer
}

\section{This is the author's manuscript}

Original Citation:

Availability:

This version is available http://hdl.handle.net/2318/58479

since

Terms of use:

Open Access

Anyone can freely access the full text of works made available as "Open Access". Works made available under a Creative Commons license can be used according to the terms and conditions of said license. Use of all other works requires consent of the right holder (author or publisher) if not exempted from copyright protection by the applicable law. 


\section{Age at Surgery for Undescended Testis and Risk of Testicular Cancer}

\author{
Andreas Pettersson, M.D., Lorenzo Richiardi, M.D., Ph.D., \\ Agneta Nordenskjold, M.D., Ph.D., Magnus Kaijser, M.D., Ph.D., \\ and Olof Akre, M.D., Ph.D.
}

\section{BACKGROUND}

Undescended testis, which is a risk factor for testicular cancer, is usually treated surgically, but whether the age at treatment has any effect on the risk is unclear. We studied the relation between the age at treatment for undescended testis and the risk of testicular cancer.

\section{METHODS}

We identified men who underwent orchiopexy for undescended testis in Sweden between 1964 and 1999. Cohort subjects were identified in the Swedish Hospital Discharge Register and followed for the occurrence of testicular cancer through the Swedish Cancer Registry. Vital statistics and data on migration status were taken from the Register of Population and Population Changes for the years 1965 through 2000. We estimated the relative risk of testicular cancer using Poisson regression of standardized incidence ratios, comparing the risk in the cohort with that in the general population. We also analyzed the data by means of Cox regression, using internal comparison groups.

\section{RESULTS}

The cohort consisted of 16,983 men who were surgically treated for undescended testis and followed for a total of 209,984 person-years. We identified 56 cases of testicular cancer during follow-up. The relative risk of testicular cancer among those who underwent orchiopexy before reaching 13 years of age was 2.23 ( $95 \%$ confidence interval [CI], 1.58 to 3.06), as compared with the Swedish general population; for those treated at 13 years of age or older, the relative risk was 5.40 (95\% CI, 3.20 to 8.53). The effect of age at orchiopexy on the risk of testicular cancer was similar in comparisons within the cohort.

\section{CONCLUSIONS}

Treatment for undescended testis before puberty decreases the risk of testicular cancer.

From the Clinical Epidemiology Unit, Department of Medicine (A.P., M.K., O.A.) the Division of Pediatric Surgery, Department of Women and Child Health (A.N.), the Department of Molecular Medicine and Surgery (A.N.), and the Department of Clinical Sciences, Danderyds Hospital (M.K.), Karolinska Institutet, Stockholm; and the Unit of Cancer Epidemiology, Center for Experimental Research and Medical Sciences and Center for Oncologic Prevention, University of Turin, Turin, Italy (A.P., L.R.). Address reprint requests to Dr. Pettersson at the Clinical Epidemiology Unit, Karolinska University Hospital, M9:01, SE-171 76 Stockholm, Sweden, or at andreas.h.pettersson@ki.se.

N EnglJ Med 2007;356:1835-41. Copyright (๑) 2007 Massachusetts Medical Society. 
U NDESCENDED TESTIS, OR CRYPTORCHIdism, which occurs in 2 to $5 \%$ of boys born at term, is one of the most common congenital abnormalities. ${ }^{1}$ Cryptorchidism is associated with impaired fertility and is a risk factor for testicular cancer. Among men who have had undescended testis, the risk of cancer is increased two to eight times, and 5 to $10 \%$ of all men with testicular cancer have a history of cryptorchidism..$^{1,2}$ However, it is unknown whether cryptorchidism and testicular cancer have a common cause, or whether cryptorchidism is in itself a cause of testicular cancer.

Testes that are undescended at birth may descend spontaneously during early life, but seldom thereafter. By 12 months of age, about $1 \%$ of all boys have cryptorchidism. ${ }^{1,3}$ Treatment for persistent cryptorchidism is generally orchiopexy, a surgical correction in which the testicle is placed and fixed in the scrotum. There is evidence that postnatal germ-cell development deteriorates in the undescended testis after the first year, and perhaps for this reason, the risk of infertility increases with age. ${ }^{1,4,5}$ The recommended age for orchiopexy has therefore been successively lowered, and the procedure is now recommended for patients younger than 2 years old and even as young as 6 months old. ${ }^{4,6}$

The question of whether the age at treatment has any effect on the risk of testicular cancer is controversial. According to the predominant view, the mechanism leading to testicular cancer is present before birth and the risk of cancer is largely determined in utero or early in life., ${ }^{7,8}$ If this view is correct, then the age at surgical correction should not be related to the rate of testicular cancer. Some studies suggest, however, that orchiopexy at an early age decreases the risk of testicular cancer. Even so, most of these studies used retrospectively collected data, and all of them were too small to produce conclusive results. ${ }^{9-13}$ We investigated the risk of testicular cancer according to the age at orchiopexy in a cohort of almost 17,000 Swedish men who were surgically treated for cryptorchidism between 1964 and 1999.

METHODS

\section{THE REGISTRIES}

We used data from the Swedish Hospital Discharge Register to assemble the study cohort, which was followed from 1965 to 2000 through linkage to the Swedish Cancer Registry and the Register of Population and Population Changes. Linkage was performed on the basis of the national registration number, a unique personal identifier referred to in all hospital records and official registries in Sweden.

In 1964, the Swedish National Board of Health and Welfare initiated the Hospital Discharge Register, which compiles data on individual discharges from Swedish public hospitals. Virtually all patients in Sweden are treated at public hospitals, making the Discharge Register representative of hospitalizations in the Swedish population. Each record contains medical and administrative data, including the dates of admission and discharge, surgical procedures performed, the main diagnosis at discharge, and up to five contributory diagnoses. The surgical procedures were coded from 1964 to 1996 according to the Swedish Classification ofOperations and Major Procedures, first through sixth editions, and from 1997 onward according to the Classification of Surgical Procedures, 1997 edition. The diagnoses at discharge were coded according to the Swedish version of the International Classification of Diseases, with the 7th revision (ICD-7) used for the years 1964 through 1968, the 8th revision (ICD-8) for 1969 through 1986, the 9th revision (ICD-9) for 1987 through 1996, and the 10th revision (ICD-10) thereafter.

In 1964, the Discharge Register covered 6 of the 26 health care regions in Sweden. Gradually, more hospitals were included, and by 1975, 16 health care regions were fully covered ${ }^{14}$ (including the three largest cities in Sweden: Stockholm, Gothenburg, and Malmö). Since 1987, the registry has covered all hospitals in Sweden.

The Swedish Cancer Registry was established in 1958 and obtains mandatory reported data from both clinicians and pathologists on all newly diagnosed malignant neoplasms. Information on the site and histopathological features of the tumors is recorded. The registry is estimated to be more than $95 \%$ complete. ${ }^{15}$ The Register of Population and Population Changes contains the official Swedish population data, including dates of death and migration; the data have been available since 1960.

\section{THE COHORT}

We confined our study cohort to all subjects in the Discharge Register who had received a diagnosis of cryptorchidism (main or contributory dis- 
charge diagnosis ICD-7 code 757.00, ICD-8 code 752.10, ICD-9 code 752F, or ICD-10 code Q53.0, Q53.1, Q53.2, or Q53.9) between January 1964 and December 1999 and who had been treated with orchiopexy (surgical procedure code $6790, \mathrm{KFH} 00$, or KFH10) before 20 years of age. The restriction to those who underwent surgery before 20 years of age minimized the influence of selection bias due to, for instance, referral of men seeking treatment for infertility to the urology department.

One subject in whom testicular cancer had already been diagnosed, 205 subjects who emigrated from Sweden after orchiopexy and did not immigrate back to Sweden before the beginning of their follow-up, and 12 subjects with conflicting information on sex or date of orchiopexy were excluded from the study cohort, leaving 16,983 subjects for the analysis. Among 2667 (15.7\%) subjects who were surgically treated for cryptorchidism more than once, we used the date of the last admission as the index date of orchiopexy.

The study was approved by the ethics committee of the Karolinska Institute. Informed consent was not required.

\section{STATISTICAL ANALYSIS}

The members of the cohort were followed from 15 years of age or the age at orchiopexy plus 1 year, whichever occurred later, to the date of diagnosis of germ-cell testicular cancer (ICD-7 code 178), the age of 55, emigration, death, or December 31, 2000, whichever occurred first. The first year after orchiopexy was excluded to reduce the risk of selection bias. The germ-cell testicular cancers we included were seminomas and nonseminomas, the latter encompassing teratomas, choriocarcinomas, yolk-sac tumors, embryonal carcinomas, and mixed germ-cell tumors.

We estimated the relative risk of testicular cancer by calculating the standardized incidence ratio (the observed number of cases of testicular cancer divided by the expected number). Expected numbers of testicular cancer were based on the 5 -year age- and period-specific rates in the Swedish general population. We estimated $95 \%$ confidence intervals (CIs) assuming a Poisson distribution. Analyses were also stratified according to age at orchiopexy and calendar period of orchiopexy. In categorizing age at orchiopexy, we focused on the ages around puberty. Categories are therefore smaller for the group between 10 and 15 years of age and larger for ages before and after. Thirteen years of age was set a priori as the cutoff for analyses of surgery before and after puberty.

We used Cox regression analysis, with age as the temporal axis, to estimate the hazard ratio for testicular cancer associated with age at orchiopexy in comparisons within the cohort. Covariates included in the model were the calendar period of follow-up (1965 to 1990, 1991 to 1995, and 1996 to 2000), calendar period of orchiopexy, and region where the orchiopexy was performed (two categories: the three largest cities in Sweden and the rest of Sweden). There is colinearity among birth cohort, age at orchiopexy, and calendar period of orchiopexy (e.g., a child operated on at 5 years of age in 1970 must have been born in 1964 or 1965). To analyze the effect of age at orchiopexy adjusted by calendar period of orchiopexy, we therefore used only three categories for the latter variable (1964 to 1969, 1970 to 1974 , and 1975 to 1999 ), assuming no period effect after 1974 . Both visual inspection of a graph (with the log of the cumulative hazard on the y axis and the log of the survival time on the $\mathrm{x}$ axis) and a formal test based on Schoenfeld residuals $(\mathrm{P}=0.68)$ indicated that the proportional-hazard assumption was met. There was no evidence of interaction between the calendar period of follow-up and the effect of age at orchiopexy.

We also conducted a sensitivity analysis, restricting the cohort to men born between 1964 and 1980, among whom the estimate of the effect of age at orchiopexy could not be biased by the lack of information about orchiopexy before 1964 (when the Discharge Register was established) or by the termination of the follow-up at 2000 .

\section{RESULTS}

The cohort consisted of 16,983 men who were surgically treated for cryptorchidism and followed for a mean $( \pm S D)$ period of $12.4 \pm 7.4$ years, with a total of 209,984 person-years at risk. For 679 of the subjects, follow-up ended before December 31, 2000 , because of a diagnosis of testicular cancer (56), emigration (436), reaching the age of 55 years (5), or death (182). The overall mean age at orchiopexy was $8.6 \pm 3.5$ years, and the median age was 8.5 years. Table 1 lists the main characteristics of the cohort.

We identified 56 cases of testicular cancer during the follow-up period, as compared with 20 expected cases, resulting in a standardized inci- 


\begin{tabular}{|c|c|c|c|}
\hline Variable & $\begin{array}{c}\text { Men Who } \\
\text { Underwent Surgery }\end{array}$ & $\begin{array}{c}\text { Person-Years } \\
\text { of Follow-Up } \\
\text { number (percent) }\end{array}$ & $\begin{array}{c}\text { Men with } \\
\text { Testicular Cancer }\end{array}$ \\
\hline Total & $16,983(100)$ & $209,984(100)$ & $56(100)$ \\
\hline \multicolumn{4}{|l|}{ Age at orchiopexy } \\
\hline $0-2 \mathrm{yr}$ & $718(4.2)$ & $4,395(2.1)$ & $1(1.8)$ \\
\hline $3-6 y r$ & $5,139(30.3)$ & $47,303(22.5)$ & $8(14.3)$ \\
\hline $7-9 \mathrm{yr}$ & $5,047(29.7)$ & $61,172(29.1)$ & $14(25.0)$ \\
\hline $10-12 \mathrm{yr}$ & $4,417(26.0)$ & $65,339(31.1)$ & $15(26.8)$ \\
\hline $13-15 \mathrm{yr}$ & $1,217(7.2)$ & $22,884(10.9)$ & $12(21.4)$ \\
\hline $16-19 \mathrm{yr}$ & $445(2.6)$ & $8,891(4.2)$ & $6(10.7)$ \\
\hline \multicolumn{4}{|c|}{ Calendar year of orchiopexy } \\
\hline 1964-1969 & $542(3.2)$ & $14,575(6.9)$ & $12(21.4)$ \\
\hline 1970-1974 & $2,326(13.7)$ & $50,185(23.9)$ & $18(32.1)$ \\
\hline 1975-1979 & $3,780(22.3)$ & $63,030(30.0)$ & $11(19.6)$ \\
\hline 1980-1984 & $4,714(27.8)$ & $53,281(25.4)$ & 10 (17.9) \\
\hline 1985-1989 & $3,522(20.7)$ & $22,464(10.7)$ & $5(8.9)$ \\
\hline 1990-1994 & $1,823(10.7)$ & $6,002(2.9)$ & 0 \\
\hline 1995-1999 & $276(1.6)$ & $447(0.2)$ & 0 \\
\hline \multicolumn{4}{|l|}{ Year of birth } \\
\hline 1963 or earlier & $2,129(12.5)$ & $52,038(24.8)$ & $27(48.2)$ \\
\hline 1964-1969 & $3,524(20.8)$ & $64,394(30.7)$ & $14(25.0)$ \\
\hline 1970-1974 & $3,855(22.7)$ & $50,866(24.2)$ & $10(17.9)$ \\
\hline 1975-1979 & $3,687(21.7)$ & 31,293 (14.9) & $4(7.1)$ \\
\hline 1980-1985 & $3,788(22.3)$ & $11,393(5.4)$ & $1(1.8)$ \\
\hline \multicolumn{4}{|l|}{ Type of cancer } \\
\hline Seminoma & & & $23(41.1)$ \\
\hline Nonseminoma & & & 33 (58.9) \\
\hline \multicolumn{4}{|l|}{ Region* } \\
\hline Urban & $5,468(32.2)$ & $71,458(34.0)$ & $17(30.4)$ \\
\hline Nonurban & $11,515(67.8)$ & $138,526(66.0)$ & $39(69.6)$ \\
\hline
\end{tabular}

* The urban category includes Sweden's three largest cities: Stockholm, Gothenburg, and Malmö. Percentages may not total 100 because of rounding.

dence ratio of 2.75 (95\% CI, 2.08 to 3.57). The standardized incidence ratio for testicular cancer among those operated on before the age of 13 years was 2.23 (95\% CI, 1.58 to 3.06), whereas it was 5.40 (95\% CI, 3.20 to 8.53) for those treated at age 13 or later (Table 2). There were no significant differences in risk between groups below $(\mathrm{P}=$ $0.81)$ or above $(\mathrm{P}=0.68)$ the age of 13 years. The proportion of men who were 13 years of age or older at orchiopexy declined from $27.3 \%$ in the beginning of the study period to $5.4 \%$ during the late 1980s (Table 3).
Figure 1 shows the standardized incidence ratios for testicular cancer according to the calendar period of orchiopexy among men who underwent the surgery before the age of 13 years and among those who were surgically treated when they were 13 years or older. The standardized incidence ratio for all men in the cohort decreased from 8.64 (95\% CI, 4.47 to 15.10) among those operated on between 1964 and 1969 to 3.29 (95\% CI, 1.95 to 5.21) for those operated on between 1970 and 1974 , and it did not vary much after that. The relative difference between the standardized incidence 
ratios for those who underwent surgery before the age of 13 years and those in whom surgery was performed at or after the age of 13 years was close to 2 in most of the calendar periods (Fig. 1).

The within-cohort analysis of the effects of age at orchiopexy on the risk of testicular cancer were consistent with the findings obtained when the rates of testicular cancer in the study cohort were compared with Swedish national rates (Fig. 2). The adjusted hazard ratio for testicular cancer among men who were 13 years of age or older when surgery was performed, as compared with those who were younger at the time of treatment was 1.99 ( $95 \%$ CI, 1.00 to 3.95). Analyses restricted to men born between 1964 and 1980 revealed a hazard ratio of 3.56 (95\% CI, 1.34 to 9.47), based on 6 cases in which surgery was performed at 13 years of age or later and 23 cases in which surgery was performed at an earlier age.

\section{DISCUSSION}

In this cohort study of 16,983 men who were surgically treated for cryptorchidism, we found that the risk of testicular cancer among men who were treated at 13 years of age or older was approximately twice that among men who underwent orchiopexy before the age of 13 . The results indicate that early, rather than late, surgical treatment can best prevent testicular cancer in boys with cryptorchidism. The results also suggest that the ectopic position of the testis is a factor in the development of testicular cancer.

In our large cohort study, the use of strict criteria for identification of cohort members registration with both diagnosis and surgical procedure - reduced the likelihood of misclassification of cryptorchidisism. By starting follow-up 1 year after the date of surgery and by restricting the cohort to men who had been treated before reaching 20 years of age, the risk of including cohort members who already had testicular cancer should have been minimized. Moreover, use of the nationwide cancer registry to ascertain outcome virtually ensured complete follow-up.

In principle, the gradual inclusion of health care regions in the Discharge Register could have biased the results. However, the incidence of testicular cancer in Sweden is fairly homogeneous, ${ }^{16}$ and in analyses with an internal comparison group, in which we could adjust for the region, estimates of risk were similar to those in the analysis in which the general population was used
Table 2. Standardized Incidence Ratio for Testicular Cancer According to the Age at Orchiopexy among Men 15 to 55 Years of Age between 1965 and 2000.:

\begin{tabular}{lcc|}
\hline Age at Orchiopexy & $\begin{array}{c}\text { No. of Men } \\
\text { with Testicular Cancer }\end{array}$ & $\begin{array}{c}\text { Standardized Incidence } \\
\text { Ratio (95\% CI) }\end{array}$ \\
All ages & 56 & $2.75(2.08-3.57)$ \\
$0-6 \mathrm{yr}$ & 9 & $2.02(0.93-3.84)$ \\
$7-9 \mathrm{yr}$ & 14 & $2.35(1.28-3.94)$ \\
$10-12 \mathrm{yr}$ & 15 & $2.27(1.27-3.74)$ \\
$13-15 \mathrm{yr}$ & 12 & $5.06(2.61-8.84)$ \\
$16-19 \mathrm{yr}$ & 6 & $6.24(2.29-13.58)$ \\
$<13 \mathrm{yr}$ & 38 & $2.23(1.58-3.06)$ \\
$\geq 13 \mathrm{yr}$ & 18 & $5.40(3.20-8.53)$ \\
\hline
\end{tabular}

* The Swedish general population was used as the comparison group.

Table 3. Proportion of Men in the Cohort Who Were Treated at 13 Years of Age or Older.

$\begin{array}{lc}\text { Year: } & \text { Men Treated at } 13 \text { Years of Age or Older } \\ & \% \\ 1964-1969 & 27.3 \\ 1970-1974 & 14.8 \\ 1975-1979 & 10.8 \\ 1980-1984 & 7.2 \\ 1985-1989 & 5.4\end{array}$

* Data are not shown for later years because day-surgery orchiopexies were introduced in Sweden in the early 1990s.

as the comparison group. For this reason, it is unlikely that such a bias had any major influence on the results.

The strong effect of the calendar period of orchiopexy on the risk of testicular cancer (Fig. 1) suggests that unknown risk factors correlated with calendar time affect the risk estimates. The effect of age at orchiopexy on the risk of testicular cancer was, however, essentially constant over calendar periods. Consequently, it is unlikely that the factors underlying the effect of the calendar period of orchiopexy can explain the effect of age at orchiopexy on the risk of testicular cancer.

Other studies have examined the age at orchiopexy in relation to the risk of testicular cancer. ${ }^{9-13,17-20}$ Most of these investigations were casecontrol studies with small samples. Several suggest that the risk of testicular cancer increases with age at treatment, with men treated after the age of 10 to 15 years at greatest risk. ${ }^{9-13}$ In our study, 


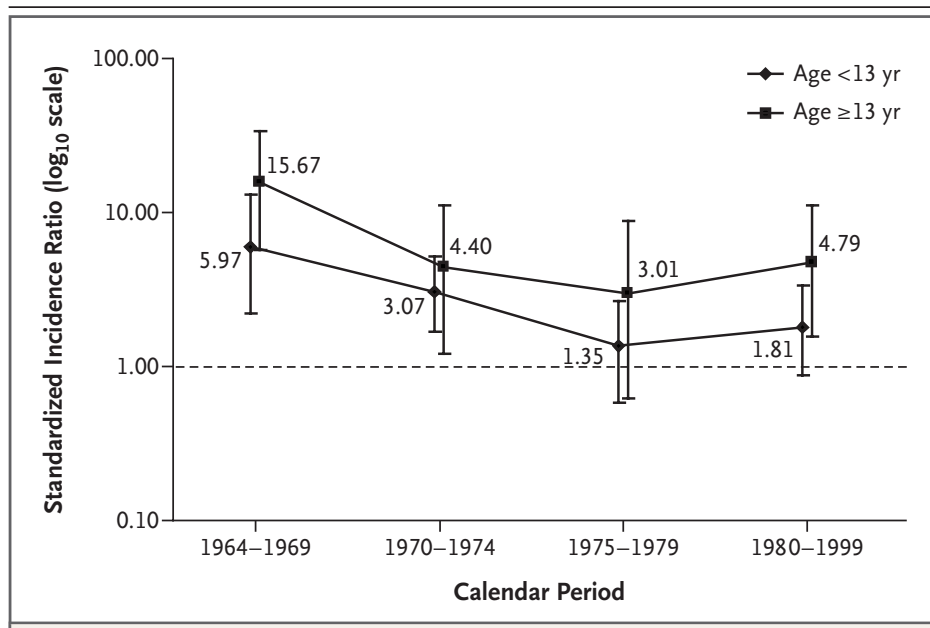

Figure 1. Standardized Incidence Ratio for Testicular Cancer According to Calendar Period of Orchiopexy among Men Treated before the Age of 13 Years and Those Treated When They Were 13 Years or Older.

The general population in Sweden was used as the comparison group. I bars denote the upper and lower limits of the $95 \%$ confidence intervals.

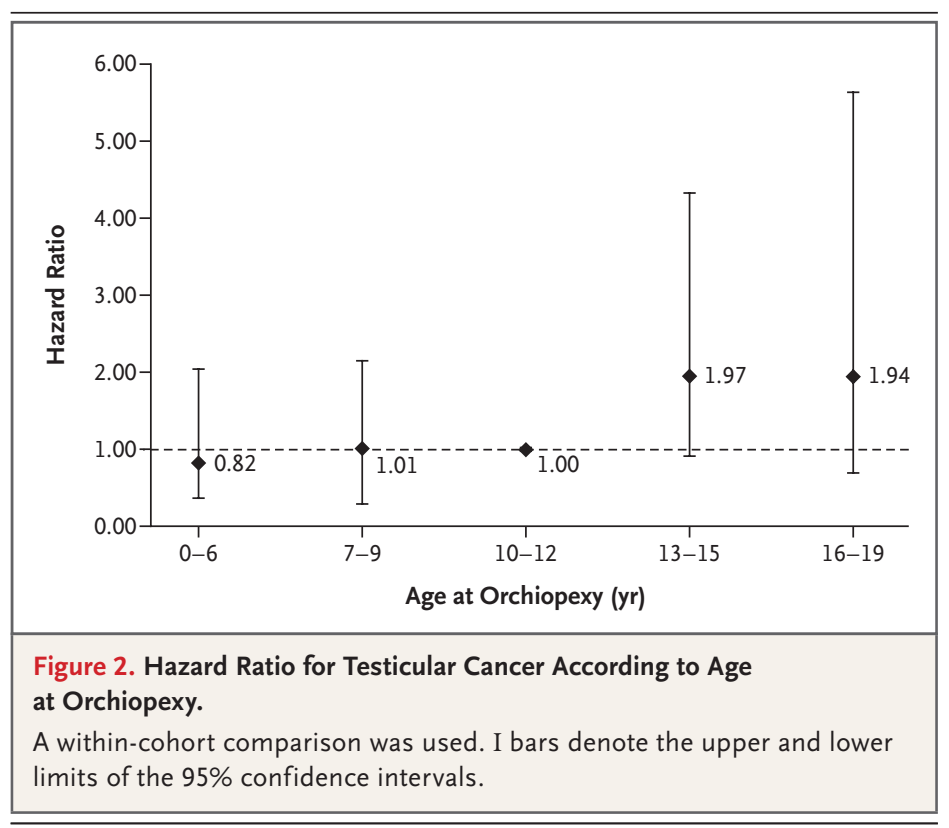

we could categorize age at orchiopexy into narrower age groups, and we found a sharp increase in risk among men treated when they were 13 to 15 years of age (or older) as compared with those treated at the age of 10 to 12 years (or at younger ages). It is unlikely that such a sharp threshold can be explained by any known confounding factor.

It could be argued that men treated at 13 years of age or older had mainly nondescending cryptorchidism, whereas a large proportion of men who were treated before the age of 13 had conditions that may not be associated with testicular cancer, such as spontaneously descending testes or retractile testis. To observe the risk pattern we found, however, $25 \%$ of the patients treated before 13 years of age would have to have had nondescending cryptorchidism, as compared with $100 \%$ of the patients treated at 13 years of age or older. It therefore seems that the ectopic location of the testis at puberty explains the increase in risk at age 13. It is also believed that the risk of germ-cell cancer of the testis is largely determined in utero. The results of our study are partly consistent with this hypothesis, since the risk was increased in the entire cohort, regardless of the age at surgical treatment. Our results, however, suggest that puberty, here defined arbitrarily as beginning at the age of 13 years, is another crucial event in testicular carcinogenesis.

Some studies have indicated that the risk of testicular cancer in the contralateral testis is increased in men with unilateral cryptorchidism, although to a lesser extent than in the undescended testicle. ${ }^{9,11,13}$ We could not assess the risk of cancer in the contralateral testis, nor could we assess the effect of age at unilateral orchiopexy on the risk of cancer in the contralateral testis, because information on laterality is not available in the registries used in our study.

Despite unambiguous recommendations for early treatment, ${ }^{4,6}$ a proportion of boys with cryptorchidism are still left untreated until much later in life. ${ }^{21,22}$ Sweden has a well-developed nationwide system to screen for cryptorchidism at several points in life, starting with neonatal care and continuing at child health care centers and at school. Since all checkups are free, attendance at these clinics should have been high. Yet in our cohort, approximately $5 \%$ of the orchiopexies in the late 1980s were performed at the age of 13 to 19 years. This proportion seems to have remained unchanged ever since. According to 2005 data from the Swedish National Board of Health and Welfare, about $6 \%$ of the orchiopexies in Sweden were performed at the age of 13 years or older. In the United Kingdom and the Netherlands, in the late 1990 s, about 10 to $20 \%$ of the orchiopexies were performed at the age of 13 years or older. ${ }^{21,22}$ According to the Swedish Cancer Registry, the cumulative incidence of testicular cancer until the age of 54 years in Sweden in 2004 was approximately $0.5 \%$. Given the relative risks in our study, we calculated that 69 boys would need to be treated before 13 years of age (instead of at or after 
that age) to avoid one case of testicular cancer in Sweden before the age of 55 years.

In summary, our results indicate that age at orchiopexy has an effect on the risk of testicular cancer in boys with an undescended testicle; the risk among those treated at 13 years of age or older was twice the risk among those who were treated at younger ages.
Supported by grants from the Swedish Cancer Society (4952B04-01XAA), the Compagnia SanPaolo/Fondazione Internazionale in Medicina Sperimentale, and the Italian Center for Research on Cancer (to Dr. Richiardi), the Stockholm County Council (to Dr. Akre), and the Swedish Research Council (K2006-73P-1526503CK, to Dr. Nordenskjold).

No potential conflict of interest relevant to this article was reported.

We thank Dr. Fredrik Granath for valuable statistical input.
REFERENCES

1. Toppari J, Kaleva M. Maldescendus testis. Horm Res 1999;51:261-9.

2. Dieckmann KP, Pichlmeier U. Clinical epidemiology of testicular germ cell tumors. World J Urol 2004;22:2-14.

3. Berkowitz GS, Lapinski RH, Dolgin SE, Gazella JG, Bodian CA, Holzman IR. Prevalence and natural history of cryptorchidism. Pediatrics 1993;92:44-9.

4. Timing of elective surgery on the genitalia of male children with particular reference to the risks, benefits, and psychological effects of surgery and anesthesia. Pediatrics 1996;97:590-4.

5. Hutson JM, Hasthorpe S. Abnormalities of testicular descent. Cell Tissue Res 2005;322:155-8.

6. Idem. Testicular descent and cryptorchidism: the state of the art in 2004. J Pediatr Surg 2005;40:297-302.

7. Ekbom A. Growing evidence that several human cancers may originate in utero. Semin Cancer Biol 1998;8:237-44.

8. Rajpert-De Meyts E. Developmental model for the pathogenesis of testicula carcinoma in situ: genetic and environmental aspects. Hum Reprod Update 2006;12: 303-23.

9. United Kingdom Testicular Cancer Study Group. Aetiology of testicular can- cer: association with congenital abnormalities, age at puberty, infertility, and exercise. BMJ 1994;308:1393-9.

10. Herrinton LJ, Zhao W, Husson G. Management of cryptorchism and risk of testicular cancer. Am J Epidemiol 2003; 157:602-5.

11. Moller H, Prener A, Skakkebaek NE. Testicular cancer, cryptorchidism, inguinal hernia, testicular atrophy, and genital malformations: case-control studies in Denmark. Cancer Causes Control 1996;7: 264-74.

12. Pottern LM, Brown LM, Hoover RN, et al. Testicular cancer risk among young men: role of cryptorchidism and inguinal hernia. J Natl Cancer Inst 1985;74:377-81. 13. Strader $\mathrm{CH}$, Weiss NS, Daling JR, Karagas MR, McKnight B. Cryptorchism, orchiopexy, and the risk of testicular cancer. Am J Epidemiol 1988;127:1013-8.

14. Health regions covered in the Swedish Inpatient Register. Stockholm: Centre for Epidemiology, National Board of Health and Welfare, 2006.

15. Bergstrom R, Adami HO, Mohner M, et al. Increase in testicular cancer incidence in six European countries: a birth cohort phenomenon. J Natl Cancer Inst 1996;88:727-33.
16. Cancer incidence in Sweden, 2004. Stockholm: Centre for Epidemiology, National Board of Health and Welfare, 2005.

17. Pike MC, Chilvers C, Peckham MJ. Effect of age at orchidopexy on risk of testicular cancer. Lancet 1986;1:1246-8.

18. Pinczowski D, McLaughlin JK, Lackgren G, Adami HO, Persson I. Occurrence of testicular cancer in patients operated on for cryptorchidism and inguinal hernia. J Urol 1991;146:1291-4.

19. Prener A, Engholm G, Jensen OM. Genital anomalies and risk for testicular cancer in Danish men. Epidemiology 1996; 7:14-9.

20. Swerdlow AJ, Higgins CD, Pike MC. Risk of testicular cancer in cohort of boys with cryptorchidism. BMJ 1997;314:150711. [Erratum, BMJ 1997;315:1129.]

21. Hack WW, Meijer RW, Van Der VoortDoedens LM, Bos SD, De Kok ME. Previous testicular position in boys referred for an undescended testis: further explanation of the late orchidopexy enigma? BJU Int 2003;92:293-6.

22. Toledano MB, Hansell AL, Jarup L, Quinn M, Jick S, Elliott P. Temporal trends in orchidopexy, Great Britain, 1992-1998. Environ Health Perspect 2003;111:129-32. Copyright @ 2007 Massachusetts Medical Society. 